\title{
The Cloacal Test: a Method for Testing Anti-androgenic Effects of Chemicals in Birds
}

\author{
Jin Xi Liang, Ryoko Otsuka*, Masaru Wada* and Yukinori Yoshimura ${ }^{1)}$ \\ Graduate School of Biosphere Science, Hiroshima University, \\ Higashi-Hiroshima 739-8528, Japan, \\ * College of Liberal Arts and Sciences, Tokyo Medical and Dental University, \\ Ichikawa 272-0827, Japan
}

\begin{abstract}
The aim of this study was to develop a method to test the anti-androgenic effects of chemicals in birds. Male Japanese quail were castrated to lead the regression of cloacal protrusion, and they were treated with testosterone or flutamide, an anti-androgenic chemical, after 3 weeks of castration. Then changes in the size of cloacal protrusion area were measured. The cloacal protrusion area increased until Day 14 in birds implanted with silastic tube containing testosterone. In testosterone-stimulated birds, the growth of cloacal protrusion was significantly suppressed by injection with a dose of $10,000 \mu \mathrm{g} / 100$ g BW of flutamide. However, significant suppressive effects of flutamide were not observed with doses lower than $10,000 \mu \mathrm{g} / 100 \mathrm{~g}$ BW. The size of cloacal protrusion reached the maximum by Day 8 followed by decreasing from Day 13 in the birds implanted with silastic plate containing $1 \mathrm{mg}$ testosterone. The growth of cloacal protrusion was significantly suppressed by daily i.p. injection with $10,000 \mu \mathrm{g}$ flutamide. These results suggest that the cloacal protrusion of Japanese quail is a useful marker to test the anti-androgenic effects of chemicals in avian species.
\end{abstract}

Key words : anti-androgenic chemical, cloacal protrusion, androgen, Japanese quail

\section{Introduction}

Endocrine disruptors are chemicals that may exert hormone-like effects, and disturb the effects of endogenous hormones, leading to the disorder of endocrine functions in animals. There are reports that some chemicals are estrogenic, whereas others exert anti-androgenic effects which may cause significant problems in the endogenous endocrine functions. Chemicals such as vinclozolin and "p,p-DDE showed anti-androgenic effects to cause abnormality of male reproductive functions and behavior in mammals (Brien et al., 2000 ; Andrate et al., 2002 ; Hotchkiss et al., 2002). Because the endocrine disruptive effects of a chemical may differ among animal species, development of the method for screening of chemicals, namely testing method whether they have endocrine disruptive potency, is needed for each animal species. Although the estrogenic effects of chemicals could be evaluated by measuring the level of vitellogenin mRNA expression in the liver (Ichikawa et al., 2003), the method to test anti-

\footnotetext{
Received : June 7, 2003, Accepted : September 3, 2003

${ }^{1)}$ Correspondence to: Y. Yoshimura, Graduate School of Biosphere Sciences, Higashi-Hiroshima 739-8528, Japan. E-mail : yyosimu@hiroshima-u.ac.jp
} 
androgenic effects of chemicals has not yet been established in avian species.

The cloacal gland of Japanese quail is a target tissue of androgen that contains androgen receptors (Massa et al., 1980 ; Kaku et al., 1993), and the cloacal region develops and protrudes in association with testicular growth in male Japanese quail. The size of the cloacal protrusion can be measured on its surface without any invasive operation. The measurement of the cloacal protrusion size has been used as an external indicator of testicular development of quail (Sachs, 1967 ; Siopes and Wilson, 1975). The cloacal protrusion is regressed by castration in matured male quail. The regressed cloacal protrusion of castrated quail could redevelop by injection of birds with testosterone, whereas administration of anti-androgenic chemicals may disturb it.

The goal of our study was to develop a method to test anti-androgenic potency of chemicals in birds. We implanted testosterone together with an anti-androgen chemical to castrated quail, and the changes in the cloacal protrusion area were measured. Two methods were tried for the implantation of testosterone, namely implantation of silastic tubes containing testosterone (Experiment 1) and silastic plate containing testosterone (Experiment 2). Flutamide that shows anti-androgenic effects in mammals (Neri et al., 1972 ; Neri and Kassem, 1984) through competitive receptor binding was used as a test-chemical for anti-androgenic effects.

\section{Materials and Methods}

The birds used in this study were male Japanese quail of approximately sixty days old. They were kept in individual cages with lighting conditions of $16 \mathrm{~L}: 8 \mathrm{D}$ and $14 \mathrm{~L}$ : 10D in Experiments 1 and 2, respectively, and provided feed and water ad libitum. They were castrated as reported by Matsunaga et al. (2002) and kept for 3 weeks, when the cloacal protrusion was completely regressed. Then subcutaneous implantation of testosterone and daily i.p. injections with or without flutamide were performed in these birds.

In Experiment 1, testosterone implants were silastic tube (Dow Corning 602-265 : $\mathrm{OD}=0.95 \mathrm{~mm}$; ID $=0.26 \mathrm{~mm}$; Corning Inc., Corning, NY) filled with crystalline testosterone (Sigma Chem. Co., MO, USA) as described by Wada (1981, 1982, 1984). The length of an implant filled with hormone was $30 \mathrm{~mm}$, and one tube was implanted in one bird because preliminary experiments using one to three implants showed that one implant was enough to cause the development of the cloaca. Corn oil was used as vehicle, and flutamide (Nippon Kayaku Co., Tokyo, Japan) was dissolved in corn oil for test solution. Vehicle (100 $\mu \mathrm{l} / 100 \mathrm{~g} \mathrm{BW})$ or test solution $(1,100$ or $10,000 \mu \mathrm{g} / 100$ $\mathrm{g}$ BW) was i.p. injected daily into each bird.

In Experiment 2, a silastic plate $(5 \times 5 \times 2 \mathrm{~mm} ; 1 \mathrm{mg}$ testosterone/plate $)$ made of a mixture of Silopot 184 (silicon type, Dow Corning Co., Kanagawa, Japan) and crystalline testosterone was subcutaneously implanted in each bird as described by Ubuka et al. (2001). Flutamide was dissolved in $0.5 \%$ carboxymethylcellulose at concentrations of 1,100 or $10,000 \mu \mathrm{g} / 100 \mu \mathrm{l}$, and $100 \mu \mathrm{l}$ of each solution or vehicle was i.p. injected daily into each bird. The average body weight was $114.9 \pm 2.4 \mathrm{~g}$ (mean \pm $\mathrm{SE}, \mathrm{n}=20$ ). Carboxymethylcellulose solution has been used as the vehicle of flutamide. 

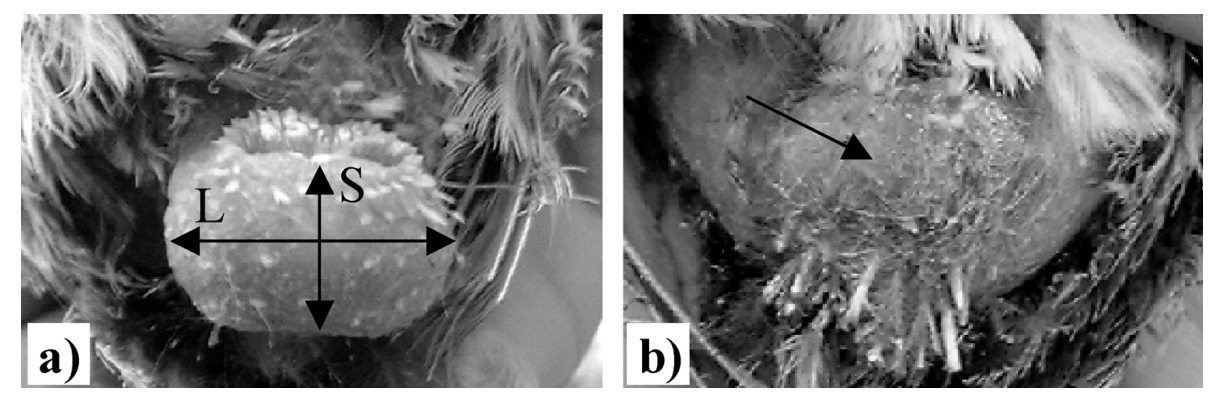

Fig. 1. The cloacal protrusion of healthy (a) and castrated (b) mature male Japanese quail. $\mathrm{L}$ and $\mathrm{S}$ show the long and short axis of the cloacal protrusion for the measurement of the area, respectively. Note the marked regression of the cloacal protrusion of castrated quail (3 weeks after castration).

The cloacal protrusion area (long axis $\mathrm{X}$ short axis of cloaca protrusion) was measured for 14 or 22 days in Experiments 1 and 2, respectively (Fig. 1). Five or six birds were used in each experimental group. Significance of differences in the value of cloacal protrusion area among different flutamide-treated groups within one measurement day was examined by one-way ANOVA, followed by Duncan's multiple range t-test. Significance was taken when $\mathrm{P}<0.05$.

\section{Results}

The cloacal region was largely protruded and showed reddish in color before castration, whereas it was significantly regressed in size and became pale in color within 3 weeks of castration (Fig. 1). In Experiment 1, the cloacal protrusion area increased until Day 14 in each experimental group except for the group treated with $1 \mu \mathrm{g}$ flutamide, in which the size of cloacal protrusion showed a peak on Day 10. The cloacal protrusion area was significantly smaller in $10,000 \mu \mathrm{g}$ flutamide-treated group than vehicle-injected one from Day 7 to 14 of treatment, whereas there was no significant difference between control and $1 \mu \mathrm{g}$ or $100 \mu \mathrm{g}$ flutamide treated groups (Fig. 2).

In Experiment 2, the cloacal protrusion area reached the maximum in each experimental group by Day 8, followed by decreasing from Day 13 . The cloacal protrusion area was significantly smaller in $10,000 \mu \mathrm{g}$ flutamide-treated group compared with control group from Day 8 to Day 13 of treatment (Fig. 3).

\section{Discussion}

We have examined whether the cloacal protrusion of Japanese quail is a useful marker to test the anti-androgenic effects of chemicals in birds. The principle of the test was that the cloacal protrusion would be regressed by castration in matured male quail, and then regrowth of the cloacal protrusion would be induced by implantation of testosterone, whereas anti-androgenic chemicals might suppress such effects of testosterone. These anti-androgenic effects may be evaluated by measuring the size of the cloacal protrusion.

The current results showing that the growth of cloacal protrusion was induced by 


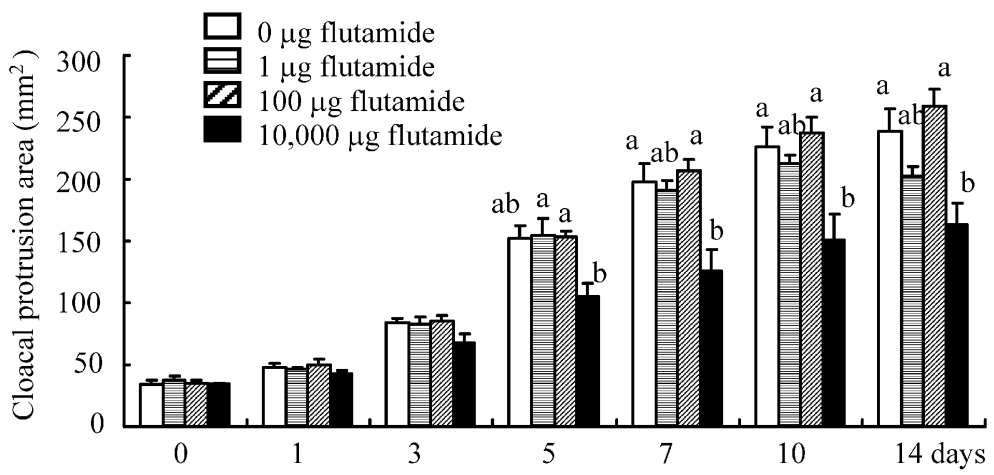

Fig. 2. Changes in the cloacal protrusion area of castrated male quail implanted with testosterone (silastic tube method) and injected with or without flutamide. Flutamide was i.p. injected daily at a dose of $0,1,100$ or 10,000 $\mu \mathrm{g} / 100 \mathrm{~g}$ BW. Each bar represents the mean $\pm \mathrm{SE}$ of the cloacal protrusion area $(n=5$ in $1 \mu$ g flutamide treatment group, and $n=6$ in the other groups). Bars with different letters are significantly different $(\mathrm{P}<0.05)$ within each examination day.

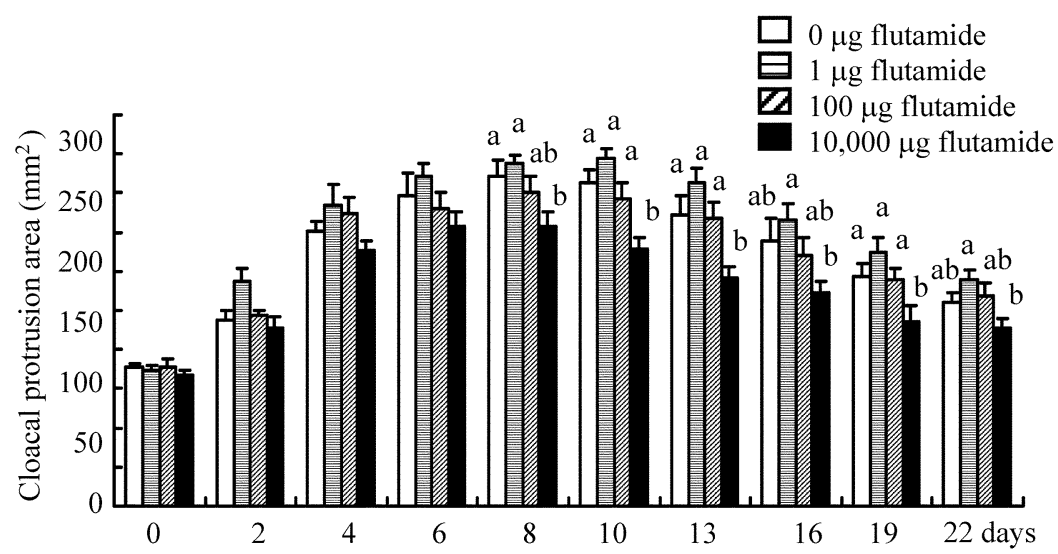

Fig. 3. Changes in the cloacal protrusion area of castrated male quail implanted with testosterone (silastic plate method) and injected with or without flutamide. Flutamide was i.p. injected daily at a dose of $0,1,100$ or $10,000 \mu \mathrm{g}$. Each bar represents the mean $\pm \mathrm{SE}(\mathrm{n}=5)$. See Fig. 2 for other explanations.

testosterone implantation support the previous reports that the cloacal gland grows under the stimulation of androgen (Sachs, 1967 ; Siopes and Wilson, 1975). Two different methods were examined for the testosterone implantation, namely implantation by silastic tubes and by silastic plates. Both implantation methods induced a significant growth of cloacal protrusion in control birds. The cloacal protrusion area increased until Day 14 in silastic tube implantation method, whereas it reached a peak by Day 8 with declining from Day 13 in silastic plate implantation method. These results suggest that both implantation methods are useful to evaluate the effects of 
testosterone on the growth of cloacal protrusion.

The cloacal protrusion area was significantly smaller in the birds injected daily with $10,000 \mu \mathrm{g}$ flutamide (per $100 \mathrm{~g} \mathrm{BW}$ or per bird) than control birds in both Experiments 1 and 2. Injection with lower dose of flutamide did not suppress the growth of cloacal protrusion induced by testosterone. Thus, it could be concluded that the higher dose of flutamide significantly suppressed the effect of testosterone on cloacal growth. Therefore, the current results suggest that fulutamide exerts anti-androgenic affects in avian as it does in mammalian species, and also the cloacal protrusion is an excellent marker to evaluate the anti-androgenic affects of chemicals.

In conclusion, we suggest that the cloacal protrusion of Japanese quail is a useful marker to test the anti-androgenic affects of chemicals in birds. In this method, castrated quail will be implanted with a silastic tube $(30 \mathrm{~mm}$ in length) filled with testosterone or silastic plate containing $1 \mathrm{mg}$ testosterone, and will be injected with different doses of test substances. The value of the cloacal protrusion area on Day 7 or Day 8 is recommended to be used to evaluate the anti-androgenic affects of chemicals because the cloacal protrusion was not undergoing declining, and significant effect of flutamide was observed on these days.

\section{Acknowledgments}

We thank Drs. T. Ubuka and A. Barua for their technical advice and critical reading of this manuscript. Thanks are also due to Nippon Kayaku Co. for kindly providing us with flutamide sample. This work was supported by Ministry of the Environment, Japan.

\section{References}

Andrate, AJM, Araujo, S, Santana, GM, Ohi, M and Dalsenter, PR. Screening for in vivo (anti) estrogenic and (anti) androgenic activities of technical and formulated deltamethrin. Regulatory Toxycology and Pharmacology, 35 : 379-382. 2002.

Brien SE, Heaton, JP, Racz, WJ and Adams MA. Effects of an environmental anti-androgen on erectile function in an animal penile erection model. Journal of Urology, $163: 1315-1321$. 2000.

Hotchkiss, AK, Ostby, JS, Vandenburgh, JG and Gray, LE Jr. Androgens and environmental antiandrogens affect reproductive development and play behavior in the Sprague-Dawley rat. Environmental Health Perspectives 110 : 435-439. 2002.

Ichikawa K, Ha Y, Tsukada A, Saito N and Shimada K. Effect of endocrine disrupters on mRNA expression of vitellogenin (VTG) II and very low density lipoprotein (apoVLDL) II in the liver of quail embryos. Journal of Poultry Science, $40: 45-52.2003$.

$\mathrm{Kaku}$, A, Chang, C, Tamura, T, Okamoto, $\mathrm{T}$ and Yoshimura, Y. Immunolocalization of androgen receptor in the cloacal gland of male Japanese quail (Coturnix coturnix japonica). Japanese Poultry Science, 30 : 413-418. 1993.

Massa, R, Davies, DT and Bottoni, L. Cloacal gland of the Japanese quail : androgen dependence and metabolism of testosterone. Journal of Endocrinology, $84: 223-230.1980$.

Matsunaga, M, Ukena, K and Tsutsui, K. Androgen biosynthesis in the quail brain. Brain Research, $948:$ 180-185. 2002.

Neri, R, Florance, K, Koziol, P and Van Cleave, S. A biological profile of a nonsteroidal antiandrogen, $\mathrm{SCH} 13521$ (4'-nitro-3'-tri-fluoromethylisobutyranilide). Endocrinology, 91 : 427-437. 1972. 
Neri, R and Kassem, N. Biological and clinical properties of antiandrogens. Progress on Cancer Research and Therapy, $31: 507-518.1984$.

Sachs, DB. Photoperiodic control of the cloacal gland of the Japanese quail. Science, $157: 201-$ 203. 1967.

Siopes, TD and Wilson, WO. The cloacal gland - an external indicator of testicular development in Coturnix. Poultry Science, 54 : 1225-1229. 1975.

Ubuka T, Sakamoto H, Li D, Ukena K, Tsutsui K. Developmental changes in galanin in lumbosacral sympathetic ganglionic neurons innervating the avian uterine oviduct and galanin induction by sex steroids. Journal of Endocrinology, 170 : 357-368. 2001.

Wada, M. Effects of photostimulation, castration, and testosterone replacement on daily patterns of calling and locomotor activity in Japanese quail. Hormones and Behavior, $15: 270-281$. 1981.

Wada, M. Effects of sex steroids on calling, locomotor activity, and sexual behavior in castrated Japanese quail. Hormones and Behavior, 16 : 147-157. 1982.

Wada, M. Effects of ventricularly implanted sex steroids on calling and locomotor activity in castrated male Japanese quail. Hormones and Behavior, 18 : 130-139. 1984. 